\title{
Endogenous Adenosine Mediates the Presynaptic Inhibition Induced by Aglycemia at Corticostriatal Synapses
}

\author{
Paolo Calabresi,, ${ }^{1}$ Diego Centonze, ${ }^{1}$ Antonio Pisani, ${ }^{1,2}$ and Giorgio Bernardi ${ }^{1,2}$ \\ ${ }^{1}$ Clinica Neurologica, Universitá di Roma Tor Vergata, Dipartimento Sanitá, 00173 Rome, Italy, and Ospedale Santa \\ Lucia, Rome, Italy
}

\begin{abstract}
Energy deprivation, as a result of aglycemia, leads to depression of the central synaptic transmission. Endogenous adenosine has been implicated in this depressant effect. We have studied the possible involvement of endogenous adenosine in the depression of corticostriatal excitatory transmission induced by glucose deprivation by using intracellular recordings in brain slices. After stimulation of corticostriatal fibers, EPSPs were recorded from striatal spiny neurons. Adenosine $(3-300 \mu \mathrm{M})$ or brief periods $(5-10 \mathrm{~min})$ of aglycemia reduced the EPSP amplitude but did not alter the membrane potential and the resistance of the recorded cells. These inhibitory effects were not associated with an alteration of the postsynaptic sensitivity to exogenous glutamate but were coupled with an increased paired-pulse facilitation, suggesting the involvement of presynaptic mechanisms. A delayed postsynaptic membrane depolarization/inward current was detected after 15-20 min of glucose deprivation. The presynaptic inhibitory effects induced by adenosine and
\end{abstract}

aglycemia were both antagonized either by the nonselective adenosine receptor antagonist caffeine $(2.5 \mathrm{~mm})$ or by the $A 1$ receptor antagonists 8-cyclopentyl-1,3-dimethylxanthine (CPT, $1 \mu \mathrm{M})$ and 1,3-dipropyl-8-cyclopentylxanthine (CPX, $300 \mathrm{~nm})$. Conversely, these antagonists affected neither the delayed membrane depolarization/inward current nor the underlying conductance increase produced by glucose deprivation. The ATP-sensitive potassium channel blockers tolbutamide (1 mM) and glipizide (100 nM) had no effect on the aglycemia-induced decrease of EPSP amplitude. Our data demonstrate that endogenous adenosine acting on A1 receptors mediates the presynaptic inhibition induced by aglycemia at corticostriatal synapses, whereas ATP-dependent potassium channels do not play a significant role in this presynaptic inhibition.

Key words: adenosine; aglycemia; ischemia; excitatory amino acids; synaptic transmission; glutamate
Clinical consequences of glucose deprivation are the suppression of encephalographic activity, rapid loss of consciousness, and irreversible neuronal injury (Auer et al., 1984; Kalimo et al., 1985; Auer and Siesjo, 1988). Depression of excitatory synaptic transmission during aglycemia has been reported in different brain areas (Bachelard et al., 1984; Burke and Nadler, 1989; Crepel et al., 1992; Shoji, 1992). This decrease might be produced by different mechanisms: (1) a reduction in the release of excitatory amino acids from the synaptic terminals, (2) an alteration of postsynaptic glutamate receptors, and (3) an abnormal coupling of postsynaptic receptors with synaptic conductances. Alternatively, a decrease of the electrochemical forces on ions involved in generating synaptic currents also might contribute to the aglycemia-induced depression of excitatory synaptic transmission (Martin et al., 1994).

Experimental evidence suggests that endogenous adenosine might represent a possible pathogenetic factor in the aglycemiainduced depression of synaptic transmission (Martin et al., 1994).

Received Jan. 8, 1997; revised March 24, 1997; accepted March 26, 1997.

This study was supported partially by grants from Consiglio Nazionale delle Ricerche (P.C.), from the Italian Ministry of Health (Progetto Finalizzeto, Ospedale Santa Lucia) (P.C.), and by Progetto Nazionale Ricerche/Neurobiologia (G.B.). We thank G. Gattoni and M. Tolu for their technical assistance. We thank Dr. M. Giorgi (L'Aquila University) for the experiments on phosphodiesterase activity. We also thank Drs. E. Ongini and S. Dionisotti (Schering Plough, Milano, Italy) for helpful discussions.

Correspondence should be addressed to Dr. Paolo Calabresi, Clinica Neurologica, Dipartimento Sanitá, Universitá di Roma Tor Vergata, Via O. Raimondo 8, 00173 Rome, Italy.

Copyright $(1) 1997$ Society for Neuroscience $0270-6474 / 97 / 174509-08 \$ 05.00 / 0$
Adenosine is released during aglycemia (Butcher et al., 1987), and the activation of adenosine receptors causes a presynaptic inhibitory action on nerve terminals releasing excitatory amino acids in different brain areas (Malenka and Kocsis, 1988; Greene and Haas, 1991; Uchimura and North, 1991; Thompson et al., 1992; Ulrich and Huguenard, 1995). Moreover, extracellular studies have shown that adenosine receptor antagonists reduce the aglycemia-induced depression of field potentials in hippocampal slices (Zhu and Krnjevic, 1993). An alternative mechanism that might account for the aglycemia-induced depression of synaptic transmission is the possible activation of presynaptic ATP-sensitive potassium channels (Ashcroft, 1988; Freedman and Lin, 1996).

We have investigated the possible involvement of adenosine receptors and ATP-sensitive potassium channels in the aglycemiainduced depression of the excitatory transmission at corticostriatal synapses by using intracellular recordings from a brain slice preparation. Moreover, we also have investigated the presynaptic action of exogenous adenosine on striatal neurons to compare this action with the effects produced by glucose deprivation at corticostriatal synapses. Morphological findings have shown that the striatum is highly vulnerable to hypoglycemia (Kalimo et al., 1985). Because pharmacological and biochemical studies suggest that corticostriatal projection is one of the most important glutamatergic pathways in the brain (Reubi and Cuenod, 1979) (for review, see Calabresi et al., 1996), overactivity of this projection might be implicated in the pathogenesis of acute and chronic neurological disorders involving the basal ganglia (Globus et al., 1988; Beal, 1995). Stimulation of corticostriatal fibers produces 
EPSPs, which are mediated by the release of endogenous excitatory amino acids acting on ionotropic glutamate receptors localized on striatal spiny neurons (Cherubini et al., 1988; Calabresi et al., 1996). Thus, the aglycemia-induced changes of these potentials might provide information concerning the action of energy metabolism failure on the corticostriatal transmission.

\section{MATERIALS AND METHODS}

Wistar rats (150-250 gm) were used. The preparation and maintenance of coronal slices have been described previously (Calabresi et al., 1990, 1991, 1995a,b). Briefly, corticostriatal coronal slices $(200-300 \mu \mathrm{m})$ were prepared from tissue blocks of the brain with the use of a vibratome. A single slice was transferred to a recording chamber and submerged in a continuously flowing Krebs' solution $\left(35^{\circ} \mathrm{C}, 2-3 \mathrm{ml} / \mathrm{min}\right.$ ) gassed with $95 \%$ $\mathrm{O}_{2} / 5 \% \mathrm{CO}_{2}$. To study glucose metabolism in striatal neurons, we deprived slices of glucose by removing glucose totally from the perfusate and by adding saccharose to balance the osmolarity. In some experiments the osmolarity was balanced by increasing the $\mathrm{NaCl}$ concentration (Jiang and Haddad, 1992). Because experiments performed by using these different procedures to replace glucose gave similar results, all of the data were pooled together. Aglycemic solutions entered the recording chamber no later than $20 \mathrm{sec}$ after a three-way tap was turned. Complete replacement of the medium in the chamber took $\sim 90 \mathrm{sec}$, as detected by the speed of diffusion of a colored solution. The composition of the control solution was (in $\mathrm{mM}$ ): $126 \mathrm{NaCl}, 2.5 \mathrm{KCl}, 1.2 \mathrm{MgCl}_{2}, 1.2$ $\mathrm{NaH}_{2} \mathrm{PO}_{4}, 2.4 \mathrm{CaCl}_{2}, 11$ glucose, and $25 \mathrm{NaHCO}_{3}$.

The intracellular recording electrodes were filled with $2 \mathrm{M} \mathrm{KCl} \mathrm{(30-60}$ $\mathrm{M} \Omega$ ). An Axoclamp 2A amplifier (Axon Instruments, Foster City, CA) was used for recordings either in current-clamp or in voltage-clamp mode. In single-microelectrode voltage-clamp mode the switching frequency was $3 \mathrm{kHz}$. The headstage signal was monitored continuously on a separate oscilloscope. Current-voltage relationships and changes in membrane conductance were detected by the application of voltage steps both in positive and negative directions (1-3 sec duration, 5-15 mV amplitude). Traces were displayed on an oscilloscope and stored on a digital system. For synaptic stimulation, bipolar electrodes were used. These stimulating electrodes were located either in the cortical areas close to the recording electrode or in the white matter between the cortex and the striatum to activate corticostriatal fibers. Quantitative data on modifications induced by aglycemia are expressed as a percentage of the controls, the latter representing the mean of responses recorded during a stable period (15-20 min) before the aglycemic phase. Values given in the text and in the figures are mean \pm SEM of changes in the respective cell populations. Student's $t$ test (for paired and unpaired observations) was used to compare the means. Drugs were applied by dissolving them to the desired final concentration in the saline and by switching the perfusion from control saline to drug-containing saline. Glutamate also was applied by ejecting (pressure application; Picospritzer, General Valve, Fairfield, $\mathrm{NJ}$ ) a few nanoliters of a $10-100 \mathrm{~mm}$ solution from the tip of a blunt pipette beneath the surface of the superfusing solution and just above the tissue slice. 6-Cyano-7-nitroquinoxaline-2,3-dione (CNQX) was obtained from Tocris Cookson (Bristol, UK). Adenosine and D-2-amino-5phosphonovalerate (D-APV) were obtained from Sigma (St. Louis, MO). Caffeine, CPT, and CPX were purchased from RBI (Natick, MA). Glipizide and tolbutamide were gifts from Dr. N. B. Mercuri (S. Lucia, Rome). CGS 15943 was a gift from Drs. Ongini and Dionisotti (Schering Plough, Milano, Italy).

\section{RESULTS}

\section{Properties of the recorded cells}

In the present study, data from 110 intracellularly recorded striatal spiny neurons were included. The membrane properties of these neurons previously have been described in vitro (Kita et al., 1984; Calabresi et al., 1987, 1990, 1991, 1995a,b; Kawaguchi et al., 1989; Wilson, 1993; Surmeier et al., 1994). The membrane potential of the recorded cells was $-84 \pm 5 \mathrm{mV}$. Input resistance was $39 \pm 8 \mathrm{M} \Omega$. All of the recorded cells were silent at rest and showed membrane rectification and tonic firing activity during depolarizing current pulses. Stimulation of the corticostriatal fibers produced an EPSP that was fully blocked by coadministration of $10 \mu \mathrm{M}$ CNQX plus $30 \mu \mathrm{M}$ APV $(n=5)$ (data not shown). These physiological and pharmacological characteristics are in agreement with previous findings indicating that cortically evoked EPSPs are mediated by the release of excitatory amino acids within the striatum (for review, see Calabresi et al., 1996).

\section{Effect of exogenous adenosine on corticostriatal EPSPs}

Bath application of adenosine produced a dose-dependent and reversible inhibition of corticostriatal EPSPs (Fig. 1A,C,D). This inhibitory action was coupled neither with alterations of intrinsic membrane properties such as resting membrane potential and current-voltage relationship $(n=8$; Fig. $1 B)$ nor with changes of the postsynaptic sensitivity to local pressure applications of exogenous glutamate (in control medium: $25 \pm$ $9 \mathrm{mV}, n=5$; in $30 \mu \mathrm{M}$ adenosine: $26 \pm 10 \mathrm{mV}, n=5 ; p>0.05)$. As shown in Figure 2, the inhibitory action of adenosine was antagonized by either CPT or by CPX (data not shown), adenosine A1 receptor antagonists. In fact, the adenosineinduced depression of EPSP amplitude $(30 \mu \mathrm{M}$ adenosine $=$ $-56 \pm 9 \%)$ was reduced to $-14 \pm 5 \%$ in $1 \mu \mathrm{M} \mathrm{CPT}(n=4, p<$ $0.001)$ and to $-12 \pm 4 \%$ in $300 \mathrm{~nm} \mathrm{CPX}(n=4, p<0.001)$. These concentrations of CPT (Fig. 2) and of CPX (data not shown) not only antagonized the inhibitory action of adenosine, but they also induced a slight but significant increase of the control EPSP amplitude (CPT: $+15 \pm 4 \%, n=8, p<0.01$; CPX: $+14 \pm 5 \%, n=8, p<0.01)$. Neither CPT nor CPX affected the intrinsic membrane properties of the five recorded cells $(p>0.05)$. In fact, the resting membrane potential was $-85 \pm 6 \mathrm{mV}$ in CPT $(n=8)$ and $-84 \pm 5 \mathrm{mV}$ in CPX $(n=8)$, whereas the input resistance was $38 \pm 6 \mathrm{M} \Omega$ in CPT $(n=8)$ and $38 \pm 6 \mathrm{M} \Omega$ in $\mathrm{CPX}(n=8)$.

\section{Effect of aglycemia on corticostriatal EPSPs}

Glucose deprivation produced a progressive decrease of the EPSP amplitude. This inhibitory action mimicked the adenosineinduced depression of corticostriatal transmission. In fact, brief periods of aglycemia (5-10 $\mathrm{min}$ ) produced a depression of the EPSP amplitude that was not coupled with changes of the membrane potential, current-voltage relationship, and responses to the application of exogenous glutamate (Fig. 3). Longer periods of aglycemia (15-20 min) produced a further decrease of the EPSP amplitude (Figs. 4, 5, filled circles). However, in this case the effect on synaptic transmission was coupled with a progressive membrane depolarization $(n=20$; Fig. $5 B)$ or an inward current that was associated with an increased membrane conductance ( $n=12$; data not shown). Both the early synaptic inhibition and the delayed membrane depolarization induced by glucose deprivation were fully reversible after the washout of the aglycemic solutions.

\section{Adenosine receptor antagonists on aglycemia-induced synaptic depression}

To investigate the possible role of endogenous adenosine in the aglycemia-induced decrease of corticostriatal EPSP, we applied the glucose-free medium after the incubation of the slices in the presence of adenosine receptor antagonists. The aglycemiainduced depression of EPSP was reduced by $0.2 \mathrm{~mm}$ caffeine $(n=$ $5, p<0.001$ ), a nonselective adenosine receptor antagonist (Fig. $4)$, and by the A1 adenosine receptor antagonists CPT ( $1 \mu \mathrm{M}, n=$ $7, p<0.001$; Fig. 5) and CPX (300 nм, $n=6, p<0.001$; Fig. 5). CPT $(n=6, p>0.05)$ and CPX $(n=7, p>0.05)$ altered neither the membrane depolarization/inward current induced by glucose deprivation (Fig. 5B) nor the membrane conductance increase 

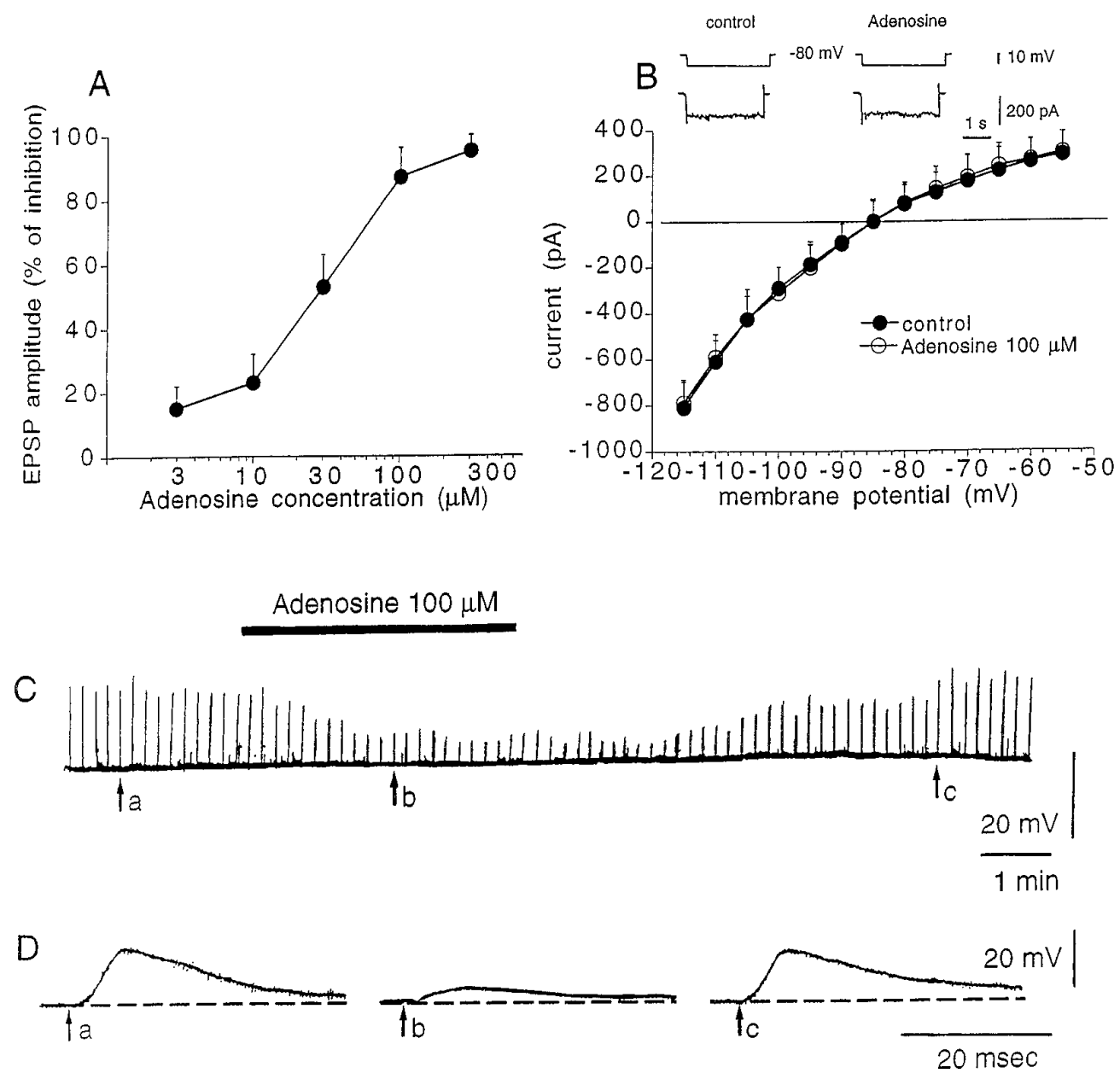

Figure 1. Exogenous adenosine mediates a presynaptic inhibitory effect at corticostriatal synapses. $A$, The graph shows a dose-response curve for the adenosine-induced inhibition of the EPSP amplitude. Each data point was obtained from at least four single experiments. $B$, The graph shows the currentvoltage relationship measured in several spiny striatal neuron before ( filled circles) and during the application of 100 $\mu \mathrm{M}$ adenosine (5 min of application, open circles). The points were obtained by measuring the steady-state current during the application of voltage steps (1-3 sec duration) both in positive and negative directions from the holding potential. Each data point was obtained from at least four single observations. The horizontal line indicates the 0 current level at the resting membrane potential $(-85 \mathrm{mV})$. The inset shows an example of a voltage step producing a current response that is not altered by adenosine $(5 \mathrm{~min}, 100 \mu \mathrm{M})$. $C$, The trace shows the chart record of the membrane potential and EPSP amplitude (upward deflections) before, during (black bar), and after the application of $100 \mu \mathrm{M}$ adenosine. The resting membrane potential (RMP) was $-86 \mathrm{mV}$. $D$, The traces show EPSPs recorded at high sweep speed before $(a)$, during $(b)$, and after $(c)$ application of $100 \mu \mathrm{M}$ adenosine (at the time indicated in $C$ ). coupled with these electrophysiological events (data not shown). We also tested the effects of CGS 15943, a nonxanthine derivative showing both A1 and A2 adenosine receptor antagonist action. This compound, in fact, does not show inhibitory activity on phosphodiesterases (Dionisotti et al., 1994). Incubation of the slices with $1 \mu \mathrm{M}$ CGS 15943 prevented the inhibitory actions of both exogenous adenosine and aglycemia on the EPSP amplitude. In fact, in the presence of this antagonist the depression of the EPSP amplitude induced by $30 \mu \mathrm{M}$ adenosine was reduced to $-14 \pm 5 \%(n=3)$, whereas the depression induced by $10 \mathrm{~min}$ of aglycemia was reduced to $-10 \pm 5 \%(n=3)$. These values were significantly different from those observed in control medium $(p<0.001)$.

\section{Effect of glucose deprivation and adenosine on paired-pulse facilitation}

Paired-pulse modification of neurotransmission has been studied extensively and is attributed to a presynaptic change in release probability (Manabe et al., 1993; Schulz et al., 1994). An increase in the ratio of the second pulse response to the first pulse response (EPSP2/EPSP1) indicates a decrease in the release probability. The decrease in transmitter release probability is consistent with the observations that manipulations depressing transmitter release usually increase the magnitude of this ratio. Therefore, we measured the magnitude of EPSP2/EPSP1 before, during, and after the application of glucose-free medium and of adenosine. Synaptic responses to a pair of stimuli were recorded with interstimulus interval of $60 \mathrm{msec}$. As shown in Figure 6, the application of glucose-free medium reversibly increased the magnitude of EPSP2/EPSP1 in all of the neurons tested $(n=7, p<0.001)$. This effect also was mimicked by exogenous adenosine $(n=6, p<$ 0.001; Fig. 6).

\section{Blockers of ATP-dependent potassium channels on aglycemia-induced synaptic depression}

Because it has been postulated that ATP-dependent potassium channels might play a role in the decrease of excitatory transmission during energy deprivation (Ashcroft, 1988; Martin et al., 1994; Freedman and Lin, 1996), we have studied whether the incubation of the slice in the presence of the ATP-dependent potassium channel blockers tolbutamide and glipizide could affect the aglycemia-induced depression of corticostriatal transmission. Tolbutamide ( $1 \mathrm{~mm}, n=5, p>0.05)$ and glipizide $(100 \mathrm{nM}, n=$ $5, p>0.05)$ failed to alter the inhibitory action of glucose deprivation (Fig. 7). Moreover, these antagonists did not modify the intrinsic membrane properties of the recorded cells and the EPSP amplitude measured under control conditions.

\section{DISCUSSION}

\section{Main findings}

The present study demonstrates that adenosine as well as brief periods (5-10 min) of glucose deprivation exert a prominent presynaptic inhibitory action at corticostriatal synapses. In fact, in both of these conditions the reduction of the EPSP amplitude was associated neither with alterations of postsynaptic intrinsic mem- 


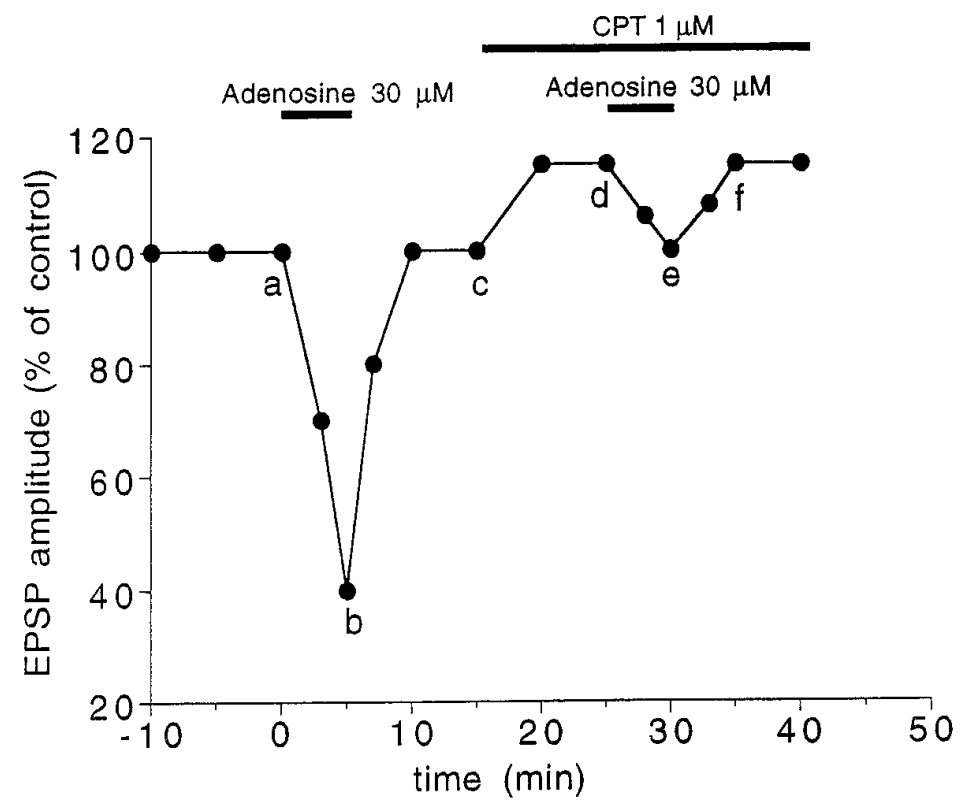

Figure 2. Adenosine A1 receptors mediate the presynaptic inhibition induced by exogenous adenosine. The graph shown at the top represents a single experiment in which, under control conditions, bath application of $30 \mu \mathrm{M}$ adenosine strongly depressed EPSP amplitude, whereas in the presence of $1 \mu \mathrm{M}$ CPT this inhibitory action was reduced significantly. Note that CPT produced a slight increase of the EPSP amplitude. Single traces at the bottom were obtained from the same experiment shown in the graph. RMP was $-85 \mathrm{mV}$.

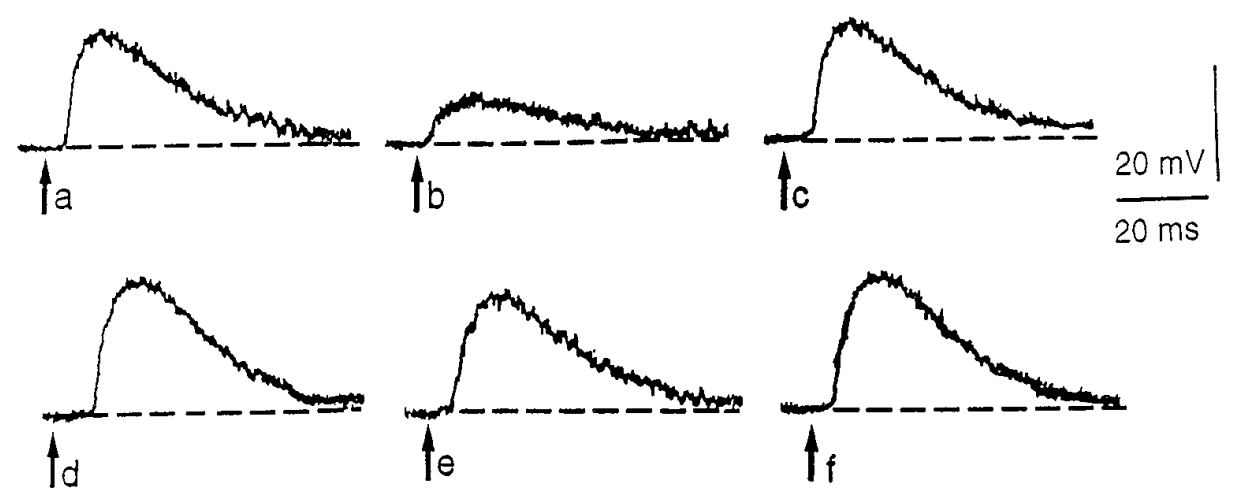

brane properties of the recorded neurons nor with changes of the postsynaptic sensitivity to exogenous glutamate. A presynaptic site of action for both adenosine and aglycemia is suggested also by the increase in paired-pulse facilitation. A presynaptic inhibitory action of adenosine on corticostriatal transmission has been postulated previously (Malenka and Kocsis, 1988; Lovinger and Choi, 1995). Accordingly, our intracellular experiments clearly demonstrate that this presynaptic inhibition is not coupled with significant changes of the postsynaptic properties that we measured. Moreover, we have shown that endogenous adenosine plays a major role in the aglycemia-induced presynaptic inhibition of glutamate release at corticostriatal synapses. In fact, this depressant effect was greatly reduced either by caffeine, a nonselective adenosine receptor antagonist, or by CPT and CPX, adenosine A1 receptor antagonists. Accordingly, the presence of adenosine A1 receptors located on corticostriatal terminals has been postulated previously (Alexander and Reddington, 1989). Interestingly, we also found that adenosine A1 receptor antagonists produced, per se, a slight but significant increase of EPSP amplitude, suggesting that endogenous adenosine does influence corticostriatal transmission not only during energy deprivation but also in physiological conditions. Conversely, tolbutamide and glipizide, blockers of
ATP-dependent potassium channels, did not affect the presynaptic inhibitory action of aglycemia, suggesting that these channels might play a role in the modulation of the postsynaptic responses to energy deprivation, but they are not involved in the control of glutamate release in the striatum during aglycemia. The latter observation is in line with data obtained in other brain areas showing that blockers of ATP-dependent potassium channels do not influence the synaptic changes induced by glucose deprivation (Shoji, 1992; Zhu and Krnjevic, 1993).

\section{Comparison with other studies}

Adenosine blocks excitatory synaptic transmission by suppressing transmitter release in several brain areas (Siggins and Schubert, 1981; Proctor and Dunwiddie, 1987; Greene and Haas, 1991; Scholz and Miller, 1991; Lupica et al., 1992; Prince and Stevens, 1992; Thompson et al., 1992). This presynaptic inhibitory action, however, usually is associated with postsynaptic changes such as membrane hyperpolarization and increased conductance (Siggins and Schubert, 1981; Proctor and Dunwiddie, 1987; Greene and Haas, 1991; Pape, 1992; Thompson et al., 1992). Interestingly, also in the nucleus accumbens, a brain area that shares a similar cytological organization with the dorsal striatum, adenosine- 


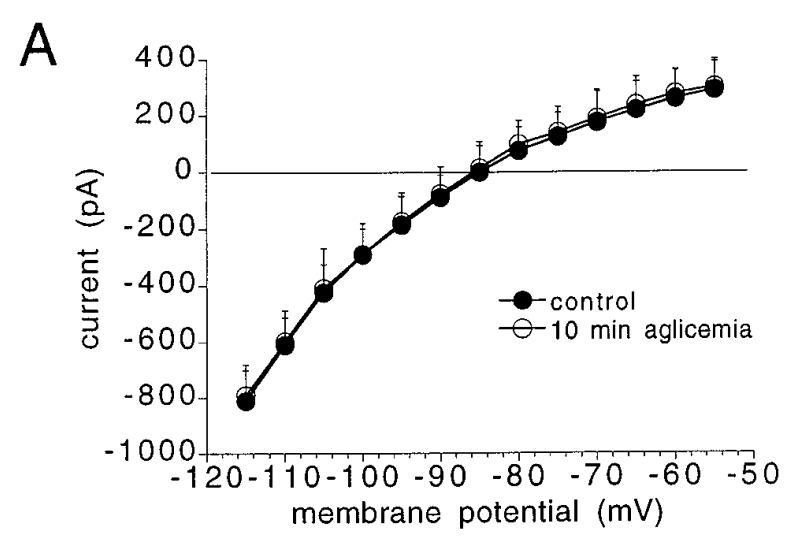

control aglycemia wash

B

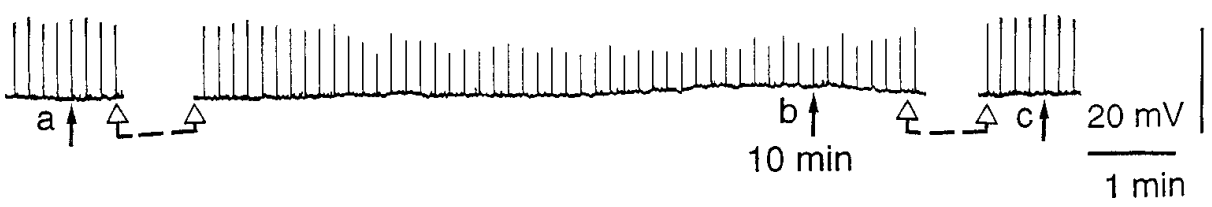

C
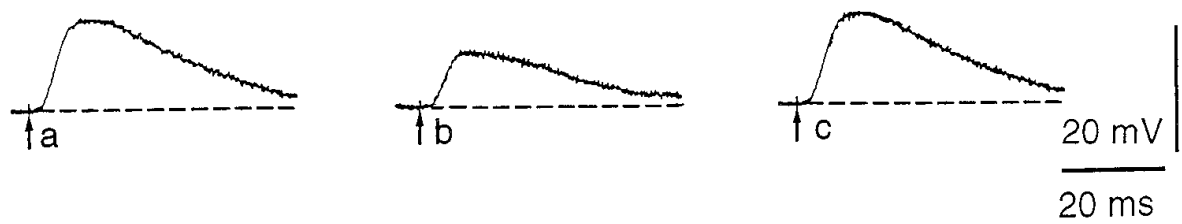

D

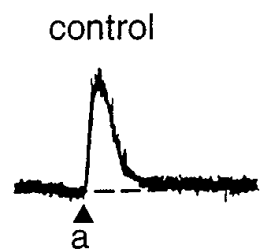

10 min aglycemia
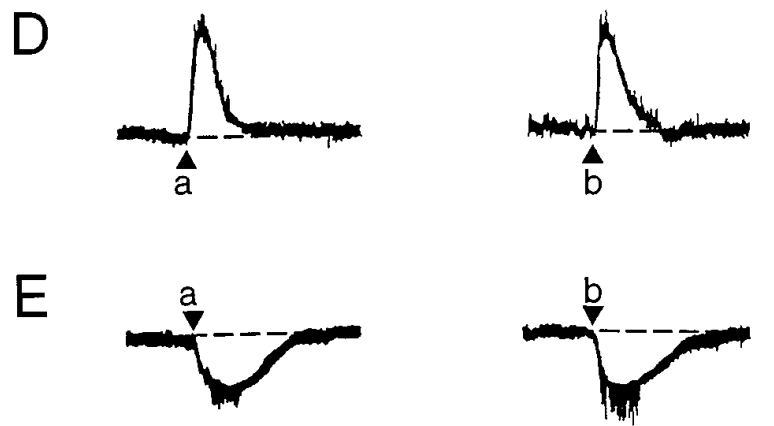
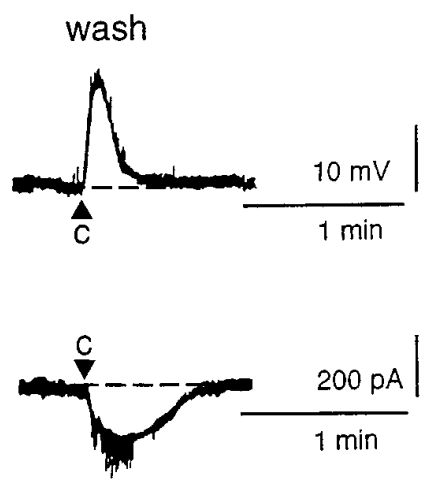

Figure 3. Brief periods of aglycemia cause presynaptic inhibition at corticostriatal synapses. $A$, The graph represents the current-voltage relationship obtained from single-microelectrode voltage-clamp experiments before (filled circles) and during (10 min, open circles) glucose deprivation. The data points were obtained by measuring the steady-state current during the application of voltage steps (1-3 sec duration) both in positive and negative directions from the holding potential. Each data point was obtained from at least four single experiments. The horizontal line indicates the 0 current level at the resting potential $(-85 \mathrm{mV}) . B$, The trace shows the chart record of the membrane potential and EPSP amplitude (upward deflections) before, during (black bar), and after the application of aglycemic medium (resting membrane potential was $-85 \mathrm{mV}$ ). $C$, The traces show EPSPs recorded at high sweep speed before $(a)$, during $(b)$, and after $(c)$ aglycemia. Traces were obtained from the same experiment shown in $B . D$, Shown are the membrane depolarizations induced by the pressure application of exogenous glutamate (1 $\mathrm{mM})$ before $(a)$, during $(10 \mathrm{~min}, b)$, and after $(10 \mathrm{~min}, c)$ glucose deprivation. RMP was $-84 \mathrm{mV}$. $E$, The traces illustrate inward currents produced by pressure applications of glutamate $(1 \mathrm{mM})$ before $(a)$, during (10 $\mathrm{min}, b)$, and after (10 min, $c$ ) aglycemia. The holding potential was constant $(-85 \mathrm{mV})$ throughout the experiment. induced blockade of excitatory synaptic transmission is coupled with a membrane hyperpolarization and an increased conductance (Uchimura and North, 1991). Thus, our finding that adenosine exerts a selective presynaptic action on spiny neurons recorded from dorsal striatum suggests that in these cells adenosine exerts a particular modulatory function by affecting presynaptic mechanisms in the absence of postsynaptic changes.

The electrophysiological effects reported in various brain regions after aglycemia strongly resemble the changes observed in the presence of exogenous adenosine. In fact, during glucose deprivation both inhibition of excitatory transmission and membrane hyperpolarization have been reported in hippocampus (Bachelard et al., 1984; Spuler et al., 1988; Burke and Nadler, 1989; Knopfel et al., 1990; Crepel et al., 1992) and in the dorsolateral septal nucleus (Shoji, 1992). We found that brief periods (5-10 min) of aglycemia, as well as exogenous adenosine, selec- tively cause presynaptic inhibition in the striatum. Longer periods of aglycemia (15-30 $\mathrm{min}$ ) were required to induce postsynaptic changes. We recently have characterized these postsynaptic changes in two neuronal striatal subtypes (Calabresi et al., 1997b). Prolonged aglycemia (15-30 min) depolarizes spiny neurons while it hyperpolarizes large aspiny interneurons; both of these membrane potential changes are mediated by postsynaptic mechanisms. Interestingly, adenosine A1 receptor antagonists reduced the aglycemia-induced presynaptic inhibitory effect (present study), but they did not antagonize the postsynaptic changes observed in these two striatal subpopulations during glucose deprivation (Calabresi et al., 1997b). Accordingly, it has been reported that A1 receptor antagonism can delay the hypoxiainduced depression of synaptically evoked excitatory potentials in hippocampal slices (Fowler, 1989; Katchman and Hershkowitz, 1993; Khazipov et al., 1995). However, if energy deprivation is 


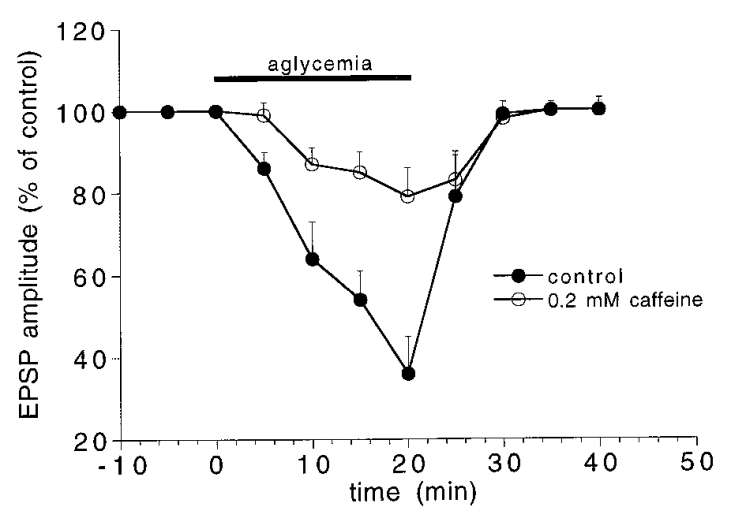

Figure 4. The inhibitory action of aglycemia on corticostriatal synaptic transmission is antagonized by caffeine. The graph represents the time course of the aglycemia-induced depression of the EPSP amplitude in control conditions ( filled circles) and in the presence of $0.2 \mathrm{~mm}$ caffeine (open circles). Each data point was obtained from at least four single experiments.

A
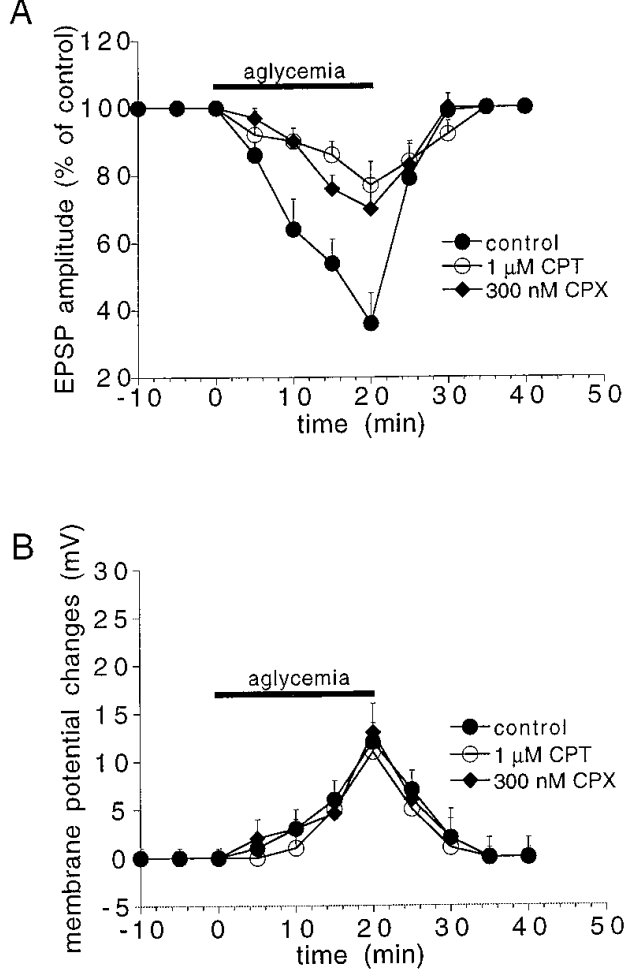

Figure 5. A1 receptor antagonists reduce the aglycemia-induced presynaptic inhibition, but not the delayed membrane depolarization, caused by glucose deprivation. $A$, The graph represents the time course of the aglycemia-induced depression of the EPSP amplitude under control conditions (filled circles), in the presence of $1 \mu \mathrm{M}$ CPT (open circles), and in the presence of $300 \mathrm{~nm}$ CPX (filled diamonds). B. The graph shows the time course of the aglycemia-induced delayed membrane depolarization under control conditions (filled circles), in the presence of $1 \mu \mathrm{M} \mathrm{CPT}$ (open circles), and in the presence of $300 \mathrm{nM}$ CPX ( filled diamonds). Each data point was obtained from at least four single experiments.

continued, synaptic depression still occurs in the presence of adenosine antagonists, albeit after a longer delay and at a slower rate (Gribkoff et al., 1990). Thus, we have to conclude that, during sustained energy metabolism failure, other mechanisms, independent of endogenous adenosine, contribute to the depression of excitatory synaptic transmission.

\section{Possible mechanisms underlying presynaptic inhibition and functional implications}

Adenosine blocks voltage-dependent calcium channels (Dolphin et al., 1986; Scholz and Miller, 1991; Mogul et al., 1993) and inhibits presynaptic calcium fluxes (Wu and Saggau, 1994). Thus, it is likely that the major mechanism underlying the aglycemiainduced EPSP inhibition is represented by the blockade of presynaptic calcium channels via the activation of adenosine A1 receptors. Alternatively, endogenous adenosine may act presynaptically to inhibit release at a point downstream from the calcium channels rather than or in addition to inhibiting the calcium channel function. It is also possible that adenosine activates presynaptic potassium channels and attenuates evoked neurotransmitter release by hyperpolarizing the presynaptic membrane.

Xanthine-like compounds might interact with phosphodiesterases. However, two findings indicate that the pharmacological effects of CPT and CPX in our experiments are not dependent on the modulation of phosphodiesterases. First, we recently have assayed the possible inhibitory activity of CPX on cGMP and cAMP phosphodiesterase in corticostriatal extracts. In fact, using the method described by Thompson and Appleman (1971) on corticostriatal extracts, we have found that $300 \mathrm{~nm}$ CPX gave very little inhibitory effect on phosphodiesterase activity: $3.2 \pm 0.2 \%$ $(n=4)$ on cAMP phosphodiesterase activity and $2.7 \pm 0.02 \%$ $(n=4)$ on cGMP phosphodiesterase activity (P. Calabresi and M. Giorgi, unpublished observation). Second, the antagonistic effects of CPX and CPT on the adenosine and aglycemia-induced reduction of the EPSP amplitude are mimicked by the nonxanthine adenosine receptor antagonist CGS 15943.

Extracellular levels of adenosine can increase after a high metabolic demand, including hypoglycemia, hypoxia, and seizure activity (Snyder, 1985; Geiger and Nagy, 1990; Greene and Haas, 1991). This increase is attributable, most likely, to net breakdown of intracellular ATP to ADP and AMP. Adenosine, derived from intracellular AMP, is released from the cell by a nucleoside transporter (Martin et al., 1994). Adenosine also may be derived from extracellular AMP, because 5'-ectonucleotidase can metabolize the AMP to adenosine extracellularly.

It has been shown recently that coactivation of metabotropic and $\beta$-adrenoreceptors on glia in area CA1 of hippocampus induces a large synergistic increase in cAMP accumulation, which provides the source for the formation of extracellular adenosine. This transmitter, in turn, activates presynaptic A1 adenosine receptors located on the terminals of Schaffer collateral and reduces the release of glutamate from these fibers (Winder et al., 1996). Thus, it is possible that glial elements play a role in the formation of endogenous adenosine during aglycemia in the corticostriatal system.

A cytoprotective role of adenosine and adenosine analogs has been demonstrated in experimentally induced cerebral ischemia (Ramkumar et al., 1995). Several mechanisms have been postulated to mediate this neuroprotection: interaction with antioxidant enzymes, activation of potassium channels, inhibition of calcium influx, and inhibition of neurotransmitters such as glutamate (for review, see Ramkumar et al., 1995). Our study suggests that the latter mechanism might play a role in the pathophysiology of corticostriatal transmission during metabolic stress. By using in vivo microdialysis in the freely moving rat, researchers recently have reported an accumulation of extracellular adenosine in the hippocampus and in the striatum during lights-off periods (Huston et al., 1996). These authors have suggested that this transmitter plays a possible role in the regulation of sleep and in some motor and nonmotor behavioral 
A

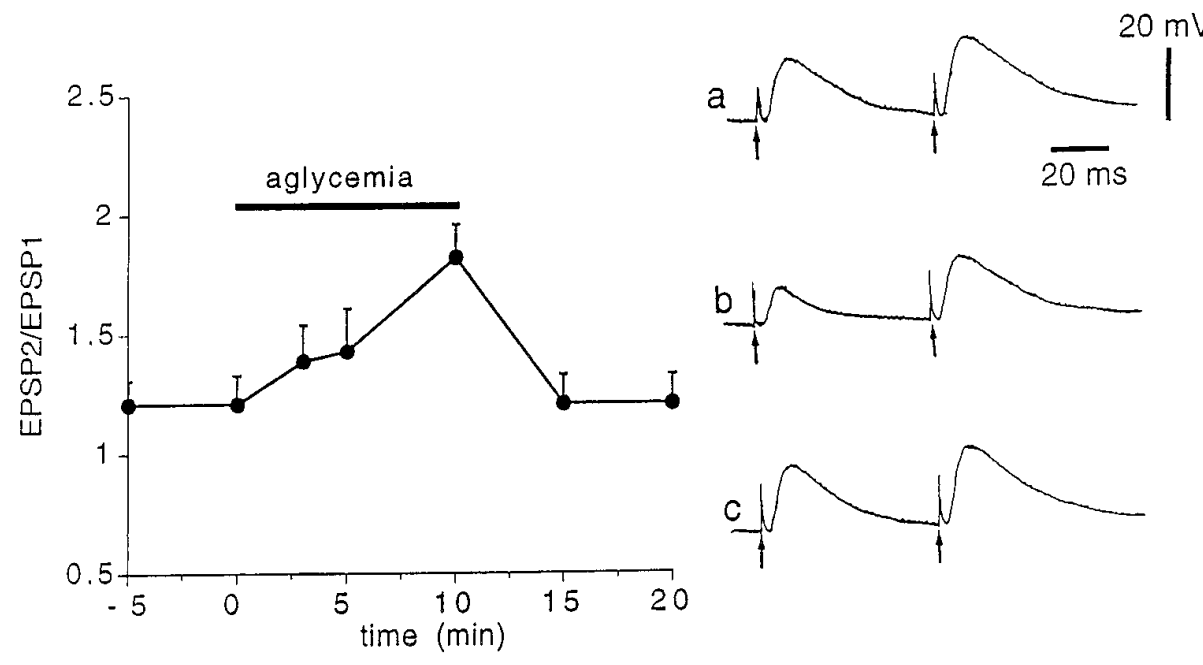

B
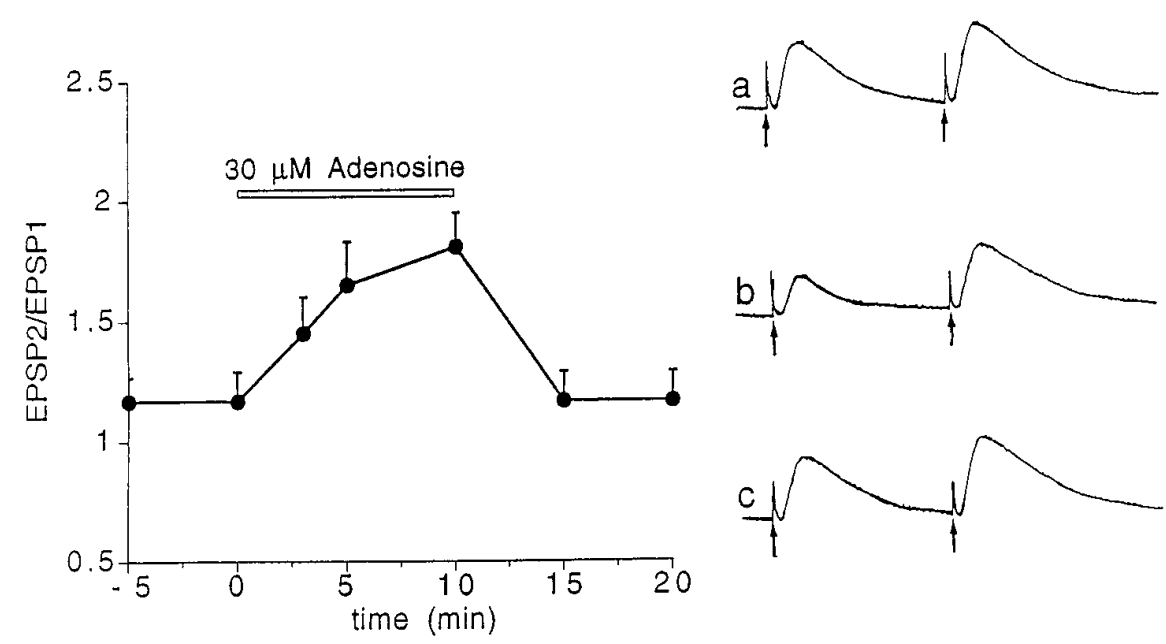

Figure 6. Aglycemia and adenosine increase the paired-pulse facilitation. $A$, The graph shows the ratio of the second pulse response to the first pulse response (EPSP2/EPSP1) before, during, and after the application of the aglycemic solution (black bar). Synaptic responses to a pair of stimuli were recorded with interstimulus interval of 60 msec. The traces on the right were obtained from a single experiment before (a), during (10 $\mathrm{min}, b)$, and after (10 min, $c$ ) glucose deprivation. RMP was $-84 \mathrm{mV} . B$, The graph shows the ratio of the second pulse response to the first pulse response (EPSP2/EPSP1) before, during, and after the application of 30 $\mu \mathrm{M}$ adenosine (white bar). The traces on the right were obtained from a single experiment before $(a)$, during $(b)$, and after (10 min, $c$ ) the application of adenosine. RMP was $-85 \mathrm{mV}$.

activities related to these brain areas (Huston et al., 1996). Thus, the adenosine-mediated depression of corticostriatal transmission during aglycemia might account for some of the behavioral changes observed after acute glucose deprivation.

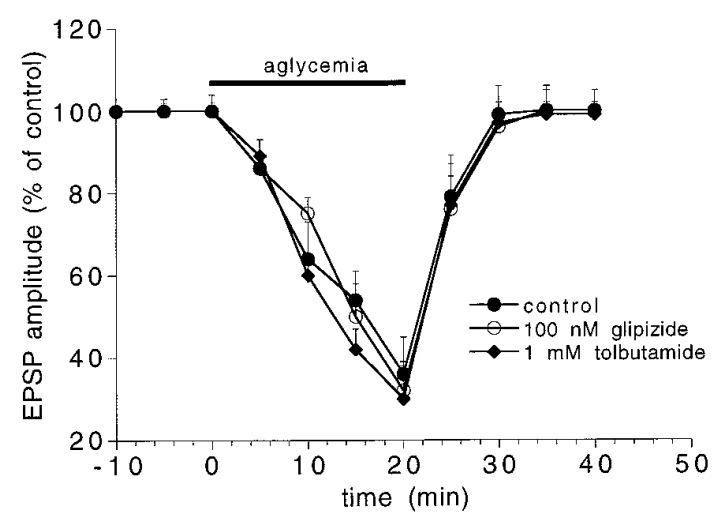

Figure 7. Blockers of ATP-dependent potassium channels fail to block the aglycemia-induced presynaptic inhibition at corticostriatal synapses. The graph shows the time course of the aglycemia-induced depression of the EPSP in control medium ( filled circles), in the presence of $100 \mathrm{~nm}$ glipizide (open circles), and in the presence of $1 \mathrm{~mm}$ tolbutamide (filled diamonds).

\section{REFERENCES}

Alexander SP, Reddington M (1989) The cellular localization of adenosine receptors in rat neostriatum. Neuroscience 228:645-651.

Ashcroft FM (1988) Adenosine 5'-triphosphate-sensitive potassium channels. Annu Rev Neurosci 11:97-118.

Auer RN, Siesjo BK (1988) Biological differences between ischemia, hypoglycemia, and epilepsy. Ann Neurol 24:699-707.

Auer RN, Olsson Y, Siesjo BK (1984) Hypoglycemic brain injury in the rat. Correlation of density of brain damage with the EEG isoelectric time: a quantitative study. Diabetes 33:1090-1098.

Bachelard HS, Cox WDG, Drower J (1984) Sensitivity of guinea-pig hippocampal granule cell field potentials to hexoses in vitro: an effect on cell excitability? J Physiol (Lond) 352:91-102.

Beal MF (1995) Aging, energy, and oxidative stress in neurodegenerative diseases. Ann Neurol 38:357-366.

Burke SP, Nadler JV (1989) Effects of glucose deficiency on glutamate/ aspartate release and excitatory synaptic responses in the hippocampal CA1 area in vitro. Brain Res 500:333-342.

Butcher SP, Hagberg H, Sanberg M, Hamberger A (1987) Extracellular purine catabolite and amino acid levels in the rat striatum during severe hypoglycemia: effects of 2-amino-5-phosphonovalerate. Neurochem Int 11:95-100.

Calabresi P, Mercuri NB, Stanzione P, Stefani A, Bernardi G (1987) Intracellular studies on the dopamine-induced firing inhibition of neostriatal neurons in vitro: evidence for D1 receptor involvement. Neuroscience 20:757-771.

Calabresi P, Mercuri NB, Bernardi G (1990) Synaptic and intrinsic con- 
trol of the membrane excitability of neostriatal neurons. II. An in vitro analysis. J Neurophysiol 63:663-675.

Calabresi P, Mercuri NB, De Murtas M, Bernardi G (1991) Involvement of GABA systems in feedback regulation of glutamate- and GABAmediated synaptic potentials in rat neostriatum. J Physiol (Lond) 440:581-599.

Calabresi P, Pisani A, Mercuri NB, Bernardi G (1995a) Hypoxia-induced electrical changes in striatal neurons. J Cereb Blood Flow Metab 15:1141-1145.

Calabresi P, Pisani A, Mercuri NB, Bernardi G (1995b) On the mechanisms underlying hypoxia-induced membrane depolarization in striatal neurons. Brain 118:1027-1038.

Calabresi P, Pisani A, Mercuri NB, Bernardi G (1996) The corticostriatal projection: from synaptic plasticity to dysfunctions of the basal ganglia. Trends Neurosci 19:19-24.

Calabresi P, De Murtas M, Bernardi G (1997a) The neostriatum beyond the motor function. Neuroscience 78:39-60.

Calabresi P, Magarinos Ascone C, Centonze D, Pisani A, Sancesario G, D' Angelo V, Bernardi G (1997b) Opposite membrane potential changes induced by glucose deprivation in striatal spiny neurons and in large aspiny interneurons. J Neurosci 17:1940-1949.

Cherubini E, Herrling PL, Lanfumey L, Stanzione P (1988) Excitatory amino acids in synaptic excitation of rat striatal neurones in vitro. J Physiol (Lond) 400:677-690.

Crepel R, Krnjevic K, Ben-Ari Y (1992) Developmental and regional differences in the vulnerability of rat hippocampal slices to lack of glucose. Neuroscience 47:579-589.

Dionisotti S, Conti A, Sandoli D, Zocchi C, Gatta F, Ongini E (1994) Effects of the new A2 adenosine receptor antagonist 8FB-PTP, an 8-substituted pyrazolo-triazolo-pyrimidine, on in vitro functional models. Br J Pharmacol 112:659-665.

Dolphin AC, Forda SR, Scott RH (1986) Calcium-dependent currents in cultured rat dorsal root ganglion neurones are inhibited by an adenosine analogue. J Physiol (Lond) 373:47-61.

Fowler JC (1989) Adenosine antagonists delay hypoxia-induced depression of neuronal activity in hippocampal brain slice. Brain Res 490:378-384.

Freedman JE, Lin Y-J (1996) ATP-sensitive potassium channels: diverse functions in the central nervous system. Neuroscientist 2:145-152.

Geiger JD, Nagy JI (1990) Adenosine deaminase $\left[{ }^{3} \mathrm{H}\right]$ nitrobenzythioinosine as markers of adenosine metabolism and transport in central purinergic systems. In: Adenosine and adenosine receptors (Williams M, ed), pp 225-288. Totowa, NJ: Humana.

Globus MYT, Busto R, Dietrich WD, Martinez E, Valdes I, Ginsberg MD (1988) Intra-ischemic extracellular release of dopamine and glutamate is associated with striatal vulnerability to ischemia. Neurosci Lett 91:36-40.

Greene RW, Haas HL (1991) The electrophysiology of adenosine in the mammalian central nervous system. Prog Neurobiol 36:329-341.

Gribkoff VK, Bauman LA, Van der Maelen CP (1990) The adenosine antagonist 8-cyclopentyltheophylline reduces the depression of hippocampal neuronal responses during hypoxia. Brain Res 512:353-357.

Huston JP, Haas HL, Boix F, Pfister M, Decking U, Schrader J, Schwarting RKW (1996) Extracellular adenosine levels in neostriatum and hippocampus during rest and activity periods of rats. Neuroscience 73:99-107.

Jiang C, Haddad GG (1992) Differential responses of neocortical neurons to glucose and/or $\mathrm{O}_{2}$ deprivation in the human and the rat. J Neurophysiol 68:2165-2173.

Kalimo H, Auer RN, Siesjo BK (1985) The temporal evolution of hypoglycemic brain damage. III. Light and electron microscopic findings in the rat caudate putamen. Acta Neuropathol (Berl) 67:37-50.

Katchman AN, Hershkowitz N (1993) Adenosine antagonists prevent hypoxia-induced depression of excitatory but not inhibitory currents. Neurosci Lett 159:123-126.

Kawaguchi Y, Wilson CJ, Emson PC (1989) Intracellular recording of identified neostriatal patch and matrix spiny cells in a slice preparation preserving cortical inputs. J Neurophysiol 62:1052-1068.

Khazipov R, Congar P, Ben-Ari Y (1995) Hippocampal CA1 lacunosummoleculare interneurons: comparison of effects of anoxia on excitatory and inhibitory postsynaptic currents. J Neurophysiol 74:2138-2148.

Kita T, Kita H, Kitai ST (1984) Passive electrical membrane properties of rat neostriatal neurons in an in vitro slice preparation. Brain Res 300:129-139.

Knopfel T, Spuler A, Grafe P, Gahwiler BH (1990) Cytosolic calcium during glucose deprivation in hippocampal pyramidal cells of rats. Neurosci Lett 117:295-299.

Lovinger DM, Choi S (1995) Activation of A1 adenosine receptors initiates short-term synaptic depression in rat striatum. Neurosci Lett 199:9-12.

Lupica CR, Proctor WR, Dunwiddie TV (1992) Presynaptic inhibition of excitatory synaptic transmission by adenosine in rat hippocampus: analysis of unitary EPSP variance measured by whole-cell recording. J Neurophysiol 12:3753-3764.

Malenka RC, Kocsis JD (1988) Presynaptic actions of carbachol and adenosine on corticostriatal synaptic transmission in vitro. $\mathrm{J}$ Neurosci 8:3750-3756.

Manabe T, Wyllie DJI, Nicoll RA (1993) Modulation of synaptic transmission and long-term potentiation: effects on paired pulse facilitation and EPSC variance in the CA1 region of the hippocampus. J Neurophysiol 70:1451-1459.

Martin RL, Lloyd HGE, Cowan AI (1994) The early events of oxygen and glucose deprivation: setting the scene for neuronal death? Trends Neurosci 17:251-257.

Mogul D, Adams M, Fox A (1993) Differential activation of adenosine receptors decreases $\mathrm{N}$-type, but potentiates $\mathrm{P}$-type $\mathrm{Ca}^{2+}$ currents in hippocampal CA3 neurons. Neuron 10:327-334.

Pape HC (1992) Adenosine promotes burst activity in guinea-pig geniculocortical neurones through two different ionic mechanisms. J Physiol (Lond) 447:729-753.

Prince DA, Stevens CF (1992) Adenosine decreases neurotransmitter release at central synapses. Proc Natl Acad Sci USA 89:8586-8590.

Proctor WR, Dunwiddie TV (1987) Pre- and postsynaptic actions of adenosine in the in vitro rat hippocampus. Brain Res 426:187-190.

Ramkumar V, Nie Z, Rybak LP, Maggirwar SB (1995) Adenosine, antioxidant enzymes, and cytoprotection. Trends Pharmacol Sci 16:283-285.

Reubi JC, Cuenod M (1979) Glutamate release in vitro from corticostriatal terminals. Brain Res 176:185-188.

Scholz KP, Miller RJ (1991) Analysis of adenosine actions on $\mathrm{Ca}^{2+}$ currents and synaptic transmission in cultured rat hippocampal pyramidal neurons. J Physiol (Lond) 435:373-393.

Schulz PE, Cook EP, Johnston D (1994) Changes in paired-pulse facilitation suggest presynaptic involvement in long-term potentiation. J Neurosci 14:5325-5337.

Shoji S (1992) Glucose regulation of synaptic transmission in the dorsolateral septal nucleus of the rat. Synapse 12:322-332.

Siggins GR, Schubert P (1981) Adenosine depression of hippocampal neurons in vitro: an intracellular study of the dose-dependent actions on synaptic and membrane potentials. Neurosci Lett 23:55-60.

Snyder SH (1985) Adenosine as a neuromodulator. Annu Rev Neurosci 8:103-124.

Spuler A, Endres W, Grafe P (1988) Glucose depletion hyperpolarizes guinea pig hippocampal neurons by an increase in potassium conductance. Exp Neurol 100:248-252.

Surmeier DJ, Wilson CJ, Eberwine J (1994) Patch-clamp techniques for studying potassium currents in mammalian brain neurons. In: Methods in neurosciences: methods for the study of ion channels, pp 39-67. San Diego: Academic.

Thompson WJ, Appleman MM (1971) Multiple cyclic nucleotide phosphodiesterase activities from rat brain. Biochemistry 10:311-316.

Thompson SM, Haas HL, Gahwiler BH (1992) Comparison of the actions of adenosine at pre- and postsynaptic receptors in the rat hippocampus in vitro. J Physiol (Lond) 451:347-363.

Uchimura N, North RA (1991) Baclofen and adenosine inhibit synaptic potentials mediated by $\gamma$-aminobutyric acid and glutamate release in rat nucleus accumbens. J Pharmacol Exp Ther 258:663-668.

Ulrich D, Huguenard JR (1995) Purinergic inhibition of GABA and glutamate release in the thalamus: implications for thalamic network activity. Neuron 15:909-918.

Wu L, Saggau P (1994) Adenosine inhibits evoked synaptic transmission primarily by reducing presynaptic calcium influx in area CA1 of hippocampus. Neuron 12:1139-1148.

Wilson CJ (1993) The generation of natural firing patterns in neostriatal neurons. In: Progress in brain research (Arbuthnott G, Emson PC, eds), pp 277-297. Amsterdam: Elsevier.

Winder DG, Ritch PS, Gereau RW, Conn PJ (1996) Novel glial-neuronal signalling by coactivation of metabotropic glutamate and betaadrenergic receptors in rat hippocampus. J Physiol (Lond) 494:743-755.

Zhu PJ, Krnjevic K (1993) Adenosine release is a major cause of failure of synaptic transmission during hypoglycemia in rat hippocampal slices. Neurosci Lett 155:128-131. 